\title{
An Analytical Study of Health System Managers' Decision-Making Models
}

\author{
Kamran Bagheri Lankarani ${ }^{1}$; Zahrataj Mohammad Alinejad ${ }^{2}$; Alireza Mooghali ${ }^{2}$; Hassan \\ Joulaei $^{1,3,} ;$ Mojtaba Akbari ${ }^{4,5} ;$ Bahram Heshmati $^{3}$ \\ ${ }_{1}^{1}$ Health Policy Research Center, School of Medicine, Shiraz University of Medical Sciences, Shiraz, IR Iran \\ ${ }^{2}$ Department of Management, Central Office, Payame-Noor University, Shiraz, IR Iran \\ ${ }_{3}^{3}$ HIV/AIDS Research Center, Shiraz University of Medical Sciences, Shiraz, IR Iran \\ ${ }^{4}$ School of Medicine, Isfahan University of Medical Sciences, Isfahan, IR Iran \\ ${ }^{4}$ School of Medicine, Isfahan University of Medical Sciences, Isfahan, IR Iran \\ *Corresponding Author: Hassan Joulaei, HIV|AIDS Research Center, Shiraz University of Medical Sciences, Shiraz, IR Iran. Tel: +987137386272, E-mail: Joulaee@sums.ac.ir
}

Received: July 6, 2015; Accepted: July 7, 2015

\begin{abstract}
Background: Cultural differences between countries may lead to different decision-making styles. This may contribute to varied style choices being used by managers (in diverse countries), who play key roles in organizations' decision-making processes.

Objectives: The present study was conducted to analyze decision-making models used by health system managers in Iran.

Patients and Methods: This was a qualitative research study conducted by interviews. The participants included 30 health system members employed at micro, intermediate and macro levels. In addition to the qualitative component of the research, after coding the responses were used. To gather qualitative data, participants were invited to illustrate their views and perceptions of how they processed allocation decisions in complex systems and what factors they applied. Data saturation was reached if an exaggerated response was found during analysis of the interview, and the response was removed from the sample.

Results: The collaborative, authority submission and consultative decision-making styles were the most widely used among Iranian health system managers. The most widely used information sources for decision-making were official information, internal experts' opinions, mental background and regulations, and upper level documents. Furthermore, $16.7 \%$ of the managers believed that they always had freedom in decision-making. There was no significant association between managers' decision-making model and their position levels in the system, or their level of education.

Conclusions: Crisis from inside or out-side the organization can affect health system managers' decision-making processes. During the decision-making process, the most common restrictions can be attributed to a shortage of manpower and other sources.
\end{abstract}

Keywords: Decision Making; Health System; Health Policy; Nurse Administrators

\section{Background}

A growing demand for health care services has been seen, nearly, in every country and health care system over the last two decades. Health systems are facing a number of challenging factors such as limited financial resources, socio-demographic changes, health care costs and health demands, which are increasing. Also, in their current working environment, people are increasingly being asked to play a role in health care decision-making. On the other hand during the past 40 years, health-related ethical, legal and socio-economic issues have made the health system more complex $(1,2)$. Therefore, the governments are responsible to meet the public's increasing need for accessible, affordable and quality health care, and they are searching for strategies to more appropriately utilize the workforce and appeal to strategies. In this context, the manager's role as the main decision maker is important.

Decision-making in practice constitutes the framework for the activities of organizational unit staff. In other words, management's decisions clarify the corporate op- eration's tasks and thus, decision-making is a critical activity (3). Decision making involves choosing one option out of several (4) in order to solve a problem. Managers need to make decisions when implementing their planning, management, guidance, and control duties. Familiarity with processes and methods of decision-making are important for managers because by applying these methods, their capability in making skilled decisions increases (5).

Results from previous studies have shown that utilizing knowledge generated from investigations has encountered problems such as varied specifications of research and its management and methodology, and also policy makers' approaches and abilities (6).

A review of previous studies has suggested that a significant relationship exists between managers' decisionmaking methods and their work experience and education levels. In personal decision-making, there was low job satisfaction; however, in other methods of decisionmaking, job satisfaction was shown to be at a higher level

Copyright (C) 2015, Shiraz University of Medical Sciences. This is an open-access article distributed under the terms of the Creative Commons Attribution-NonCommercial 4.0 International License (http://creativecommons.org/licenses/by-nc/4.0/) which permits copy and redistribute the material just in noncommercial usages, provided the original work is properly cited. 
(7). A significant relationship exists between the degree of participation in decision-making and rate of satisfaction of participation (8). There was, however, no significant relationship between management knowledge and observed collaborative, authoritative, and consultative decision-making styles (9). Studies conducted in Iran have proposed that managers apply consultative decision-making methods during design and planning, and make better use of group decision-making (10). In another research $40.4 \%$ of matrons assessed their contribution rate at an intermediate level (11). Based on previous results, factors such as the personality of the person who makes decisions, the society's culture, and the organization's values (12) also affect decision-making.

\section{Objectives}

The purpose of this study was to identify the following factors related to decision-making used by health system managers;1) the method of decision-making, 2) the sources of information for decision-making, 3) the decisionmaking criteria, 4) the freedom level of health system managers in decisions related to their work, 5) the restricting factors in health system managers' decision-making.

\section{Patients and Methods}

This qualitative research was designed to explore and reveal information about decision-making among Iranian healthcare executives. After obtaining the ethics approval from the Ethics Committee at the Fars University of medical sciences, a theoretical sample of 30 Iranian healthcare executives were selected. They were managers across multiple levels of the Iranian healthcare system and were randomly selected from different levels, i.e. the district (hospital and health center), provincial (universities of medical sciences), and national levels (health ministry) of Shiraz, Tehran, Bandar Abbas, and some small cities. Using the qualitative method semi-open interviews were conducted by the researcher in each manager's meeting room. A previous researches' questionnaire in a similar field was used in order to prepare the general questions. Accordingly, based on five criteria (method of decision-making, sources of information for decision making, freedom level of decision-making, restricting factors for decision-making, and decision-making criteria used by managers) initially 76 questions were identified; this was followed by an interview that included 20 questions, designed and customized using the projection method.

To gather qualitative data, participants were invited to discuss their views and perceptions of how they processed allocated decisions in complex systems and what factors they applied. Also they were asked to illustrate their answers with anecdotes or examples through interviews. When the managers described an effective factor used in decision-making, that factor was entered in the sample. Data saturation was reached if an exaggerated response was found during analysis of the interview, and the response was removed from the sample.

To analyze the qualitative data, generated data from interviews were reduced to different codes and categories based on the principles of analytic induction. The data was initially coded and closely examined for any similarity or difference. Category saturation was reached at interviewee number 23 , as at this point nothing new emerged from further interviewing. All statistical analysis was done using the SPSS software version 20 and the level of significance was less than 0.05 .

\section{Results}

The individual characteristics of studied managers are provided in Table 1 . The mean of managers' age was 47.3 years and the vast majority of them were females. Managers had high work experience with the mean of 23.5 years. Overall, $40 \%$ of managers were health center and hospital managers and nearly $27 \%$ of them worked as a Minister of Health and deputies in the health system. The highest degree in most of studied managers was Specialist and only $10 \%$ had a bachelor degree in health.

Overall, $46.7 \%$ of managers declared that upper-level documents were more than $90 \%$ effective in their decision-making. Overall, $26.7 \%$ of the managers believed that upstream documents were effective on decision-making "most of the time", 10\% found them effective "often", 6.7\% "sometimes" and 10\% "seldom". A total of $26.7 \%$ of the managers stated the crises effective rate to be "always"; 23.3\% answered "almost always"; 13.3\% "very often", 13.3\% "often", and $23.3 \%$ declared this effect was rare. Furthermore, $84.3 \%$ stated that crises were effective on their decision-making (P value $<0.05)$.

\begin{tabular}{|c|c|}
\hline Characteristics & Values \\
\hline Age, $y$ & $47.3 \pm 7.6$ \\
\hline \multicolumn{2}{|l|}{ Gender } \\
\hline Female & $5(16.7)$ \\
\hline Male & $25(83.3)$ \\
\hline Work Experience, yr & $23.5 \pm 6.1$ \\
\hline \multicolumn{2}{|l|}{ Job Position } \\
\hline Macro level & $8(26.7)$ \\
\hline Intermediate level & $10(33.3)$ \\
\hline Micro level & $12(40)$ \\
\hline \multicolumn{2}{|l|}{ Highest Degree } \\
\hline Specialist & $13(43.3)$ \\
\hline Doctorate & $9(30)$ \\
\hline Master of Public Health & $5(16.7)$ \\
\hline Bachelor & $3(10)$ \\
\hline
\end{tabular}


Correlations between decision-making parameters and the manager's decision-making model are reported in Table 2. As shown, the relationship of applying scientific theories in decision-making was significant only in the authority submission model $(\mathrm{P}=0.015)$. Only significant relationship was found between decision-making model using upstream with consultative $(\mathrm{P}=0.039)$ and collaborative $(\mathrm{P}=0.037)$ models.

Table 3 shows the percentage distribution of health system managers' decision making model, by position levels in system. At macro-level, managers apply a collaborative style, followed by an authority delegation style while, at intermediate-level managers initially apply a consultative style and subsequently an authority delegation style. Micro-level managers apply an authority submission style initially followed by equal use of the authoritative, collaborative, and consultative style. There was no significant association between managers' decision making model and their position levels in system (Pvalues $>0.05$ ) .

Percentage distribution of health system managers' decision-making model, by educational level is shown in Table 4. Specialist managers only selected the authority delegation, collaborative, and consultative styles, whereas in other managers, decision-making styles were authority delegation, consultative, and team-work. There was no significant association between managers' decision-making model and their education level (P values $>0.05$ ).

\begin{tabular}{|c|c|c|c|c|}
\hline \multirow{2}{*}{$\begin{array}{l}\text { Decision Making } \\
\text { Model Parameters }\end{array}$} & \multicolumn{2}{|c|}{$\begin{array}{c}\text { Decision-Making Using Up-to-Date Scientific } \\
\text { Theories }\end{array}$} & \multicolumn{2}{|c|}{$\begin{array}{c}\text { Decision-Making Using Upstream } \\
\text { Documents }\end{array}$} \\
\hline & Values & P Value & Values & PValue \\
\hline Consequential & $15(50)$ & 0.145 & $5(16.7)$ & n.s \\
\hline Authority submission & $20(66.7)$ & 0.015 & $4(13.3)$ & n.s \\
\hline Authoritative & $27(90)$ & 0.702 & $4(13.3)$ & n.s \\
\hline Collaborative & $25(83.3)$ & 0.809 & $6(20)$ & 0.039 \\
\hline Consultative & $27(90)$ & 0.702 & $3(10)$ & 0.037 \\
\hline Team & $30(100)$ & 0.444 & $7(23.3)$ & n.s \\
\hline Occasioned & $30(100)$ & 0.54 & $2(6.7)$ & n.s \\
\hline
\end{tabular}

a Abbreviation: n.s, non-significant.

$\mathrm{b}$ P values calculated using the Chi square test.

C Values are presented as No. (\%).

Table 3. Percentage Distribution of Health System Managers' Decision Making Model, by Position Levels in System a,b

\begin{tabular}{|c|c|c|c|c|}
\hline \multirow{2}{*}{$\begin{array}{l}\text { Decision Making } \\
\text { Model Parameters }^{\mathrm{c}}\end{array}$} & \multicolumn{3}{|c|}{ Decision Making Level } & \multirow{2}{*}{ PValue $^{c}$} \\
\hline & Macro Level $(\mathbf{n}=12)$ & Intermediate Level $(n=10)$ & $\operatorname{Micro} \operatorname{Level}(\mathbf{n}=8)$ & \\
\hline Consequential & $1(8.3)$ & 0 & $1(12.5)$ & n.s \\
\hline Authority submission & $4(33.3)$ & $5(50)$ & $4(50)$ & n.s \\
\hline Authoritative & $3(25)$ & $2(20)$ & $3(37.5)$ & n.s \\
\hline Collaborative & $7(58.3)$ & $3(30)$ & $3(37.5)$ & n.s \\
\hline Consultative & $2(16.6)$ & $6(60)$ & $3(37.5)$ & n.s \\
\hline Team & $2(16.6)$ & $2(20)$ & 0 & n.s \\
\hline Occasioned & 0 & $2(20)$ & $1(12.5)$ & n.s \\
\hline
\end{tabular}

a Data are presented as No.(\%).

b Abbreviation: n.s, non-significant.

${ }^{\mathrm{C}}$ Minister of health and deputies were categorized at the Macro level, rector of the university of medical sciences and deputies were categorized at the Intermediate level, and Health centers and hospitals managers and others were categorized at the Micro level.

$\mathrm{d}$ P values calculated using chi square test. 
Bagheri Lankarani Ket al.

\begin{tabular}{|c|c|c|c|c|c|}
\hline \multirow{2}{*}{$\begin{array}{l}\text { Decision Making Model } \\
\text { Parameters }\end{array}$} & \multicolumn{4}{|c|}{ Decision Making Level } & \multirow{2}{*}{ P Value } \\
\hline & Specialist $(\mathrm{n}=13)$ & Doctorate $(n=9)$ & Masters $(n=5)$ & $\operatorname{Bachelor}(\mathbf{n}=3)$ & \\
\hline Consequential & 0 & $1(11.1)$ & 0 & 0 & n.s \\
\hline Authority submission & $4(30.7)$ & $4(44.4)$ & $1(20)$ & $1(33.3)$ & n.s \\
\hline Authoritative & 0 & $4(44.4)$ & $1(20)$ & $1(33.3)$ & n.s \\
\hline Collaborative & $3(23.1)$ & $6(66.6)$ & 0 & $1(33.3)$ & n.s \\
\hline Consultative & $3(23.1)$ & $5(55.5)$ & 0 & 0 & n.s \\
\hline Team & $4(30.7)$ & $6(66.6)$ & 0 & 0 & n.s \\
\hline Occasioned & 0 & $3(33.3)$ & 0 & $1(33.3)$ & n.s \\
\hline
\end{tabular}

Table 5. Relationship Between Managers' Decision-Making Model and Information Used for Making Decisions ${ }^{\text {a }}$

\begin{tabular}{|c|c|c|c|c|c|c|c|}
\hline $\begin{array}{l}\text { Information Used for } \\
\text { Making Decisions }\end{array}$ & Consequential & $\begin{array}{l}\text { Authority } \\
\text { Submission }\end{array}$ & Authoritative & Collaborative & Consultative & Team & Occasioned \\
\hline Statistical information & 0 & $16(53.3)$ & $13(43.3)$ & $17(56.6)$ & $16(53.3)$ & $1(3.3)^{b}$ & $20(66.7)$ \\
\hline Regulations & 0 & $9(30)$ & $7(23.3)$ & $8(26.7)$ & $6(20)$ & $20(66.7)$ & 0 \\
\hline Budget information & $15(50)^{b}$ & $2(6.7)$ & 0 & 0 & 0 & 0 & 0 \\
\hline $\begin{array}{l}\text { Senior managers' } \\
\text { opinions }\end{array}$ & $15(50)$ & $5(16.6)$ & $4(13.3)$ & $5(16.6)$ & $6(20)$ & $20(66.7)^{b}$ & $10(33.3)$ \\
\hline Mental background & 0 & $7(23.3)$ & $20(66.7)^{b}$ & $11(36.6)$ & $14(46.6)$ & 0 & $20(66.7)$ \\
\hline Based on articles & $15(50)$ & $7(23.3)$ & 0 & $10(33.3)$ & $6(20)$ & 0 & $10(33.3)$ \\
\hline $\begin{array}{l}\text { Experts' opinions } \\
\text { (external) }\end{array}$ & 0 & $7(23.3)$ & $10(33.3)$ & $6(20)$ & $6(20)$ & $10(33.3)$ & 0 \\
\hline $\begin{array}{l}\text { Experts' opinions } \\
\text { (internal) }\end{array}$ & $15(50)$ & $14(46.6)$ & $23(76.6)$ & $20(66.7)$ & $16(53.3)$ & $10(33.3)$ & $30(100)$ \\
\hline
\end{tabular}

We considered different information sources used by managers during the decision-making process. Table 5 shows the results of relationship between managers decision- making model and information used for making decisions. As shown in Table 5, there exists a significant relationship, in only four cases, between decision-making style and information necessary for decision-making. In total, $16.7 \%$ of managers believed they always had freedom in decision-making, $26.7 \%$ declared they had freedom most of the time, $30 \%$ stated they sometimes had decision-making freedom, and $26.7 \%$ stated they seldom had freedom in decision-making.

\section{Discussion}

The studied managers applied various methods for decision-making. Most of the time they employed collaborative and authority delegation methods in decisionmaking; however, results oriented by team-work and occasioned methods were considered less. This result co- incided with those of Salehi et al.(13). Researchers' experiences have implied that cooperation leads to an increase in productivity and efficiency of the organization and quality of services. It also decreases conflict and negative resistance such as absence, delay and negligence (5). Managers should therefore be encouraged to use the team and collaborative decision-making methods in order to increase productivity.

We examined health system managers' decisionmaking parameters that included crises, upstream documents, and up-to-date scientific theories. We determined that there was a greater effect from crises and upstream documents on decision-making. According to the managers' views, in most cases (50\% - 70\%), crises had a considerable effect on their decision-making in the health system. The relationship between crises and all decision-making styles applied by the managers was significant and had a considerable effect on decisionmaking. 
From the managers' points of view, upstream documents were significant in consultative and collaborative styles of decision-making, and more important than other styles. Common scientific theories were less important than other decision-making parameters. Only in the authority submission style of decision-making was the relationship of common scientific theories significant.

The ability of the organization to enable effective fulfillment of responsibilities depends on the quality of the decisions made in the organization, and the quality of decisions depends on the quality of information being used $(5,14,15)$. Among information sources used by the managers in decision-making, official information, internal experts' opinions, and mental background are more welcomed, respectively. Mental background has a higher position than regulations and the opinions of external experts and senior managers. This fact, due to the difference among data received at different times, has often led to mistakes in decision-making and disturbances in the organization's purposes. The present study's results are consistent with previous results reported by Farzandipur, who stated that $55 \%$ of managers use statistical parameters (16). In the present research, we determined this rate to be $53 \%$.

According to our study most managers (40\% - 80\%) were free in their decision-making. However, according to declarations of the teams under examination, restricting factors such as the authoritative style of upstream managers or lack of access to necessary infrastructures caused health system managers' decisions to be unfulfilled.

At the micro level, the 'board of trustee' nature of private hospitals has been an important factor in their development. The change in organizational charts is more effective for managers' decision-making at this level. As such, they should refer to their superiors for most decisions. In some cases, managers have stated that each section of the hospital's staff is chosen by different people and there is no disciplined organizational chart.

Swift transitions in an organization's external environment lead to more uncertainty in decision-making. New organizations, especially those associated with generating information worldwide, such as virtual channels (like those organizations whose managers are the population under study), must continually learn new concepts. These types of organizations are faced with increasing uncertainty in identifying and solving problems. One of the methods that can help decision-making in these organizations is to pay attention to cooperation and integration. When the problem is vague or the managers do not agree, discussion, negotiation, and integration are needed. In most cases if managers recognize an issue as a problem, the organization will approach its solution (17). Asking others' opinions shows that the decision maker values others and their opinions, which leads to their increased interest and stronger motivation. Asking other's opinions can lead to their improvement, as well as increasing creativity and innovation power. In mass decision-making, people feel involved in making decisions; correctly identifying problems and barriers, equipment and resources; and face different problems with more objectivity (18).

In summary, this research showed that healthcare decision-makers relate to contextual run-time factors, which change while the system is operating, and utilize a multifaceted array of elements, methods, skills and insights in situations of action. In difficult economic times, healthcare decision-making becomes increasingly complex and traditional evidence-based methods of decision-making are not widely utilized. Thus, a set of theoretically valid and rational principles may be offered by officiallyprescribed models of decision-making or systematic evidence-based decision-making. It is suggested that in decision-making it is necessary to be aware of the lack of qualified employees, decreased team activities, decisions being based on one person's opinions, and making decisions based on mental backgrounds. In addition, in the decision-making process, proposing the correct information for decision-making, the existence of strategic planning, and freedom are suggested as ways to improve the decision-making process in the health system.

\section{Acknowledgements}

The authors gratefully acknowledge the contribution of all managers, whose participation made this study possible.

\section{Authors' Contributions}

Study concept and design: Kamran Bagheri Lankarani, Zahrataj Mohammad Alinejad and Alireza Mooghali. Analysis and interpretation of data: Kamran Bagheri Lankarani, Zahrataj Mohammad Alinejad, Hassan Joulaei and Mojtaba Akbari. Drafting of the manuscript: Kamran Bagheri Lankarani, Hassan Joulaei, Mojtaba Akbari and Bahram Heshmati. Critical revision of the manuscript for important intellectual content: Kamran Bagheri Lankarani, Alireza Mooghali and Hassan Joulaei. Statistical analysis: Hassan Joulaei, Mojtaba Akbari and Bahram Heshmati.

\section{Funding/Support}

This study was supported by the health policy research center of the school of medicine, Shiraz university of medical sciences, Shiraz, Iran.

\section{References}

1. Charles C, Gafni A, Whelan T. Decision-making in the physicianpatient encounter: revisiting the shared treatment decisionmaking model. Soc sci Med.1999;49(5):651-61.

2. Sutherland HJ, Lockwood GA, Boyd NF. Ratings of the importance of quality of life variables: therapeutic implications for patients with metastatic breast cancer. J Clin Epidemiol. 1990;43(7):661-6.

3. Jacobs JA, Clayton PF, Dove C, Funchess T, Jones E, Perveen G, et al. A survey tool for measuring evidence-based decision making capacity in public health agencies. BMC Health Serv Res. 2012;12:57.

4. Brownson RC, Fielding JE, Maylahn CM. Evidence-based public health: a fundamental concept for public health practice. Annu 
Rev Public Health. 2009;30:175-201.

5. Jacobs JA, Dodson EA, Baker EA, Deshpande AD, Brownson RC. Barriers to evidence-based decision making in public health: a national survey of chronic disease practitioners. Public Health Rep. 2010;125(5):736-42.

6. Orton L, Lloyd-Williams F, Taylor-Robinson D, O'Flaherty M, Capewell S. The use of research evidence in public health decision making processes: systematic review. PLoS One. 2011;6(7):e21704.

7. Pietersen C. Job satisfaction of hospital nursing staff. South Afr J Human Resource Manag. 2005;3(2):19-25.

8. Nuritajer M, Mahfuzpoor S, Noruzinejad F. Cooperative Decision Making of Head Nurses in Educational hospitals and Iran's Medical, Treatment Services. Health Managem Sci Res J. 2007;10(28):7-14.

9. Zohuroarvande V, Kuhestani H. Examination of the Relation between Management Knowledge and Decision Making Style of Mashad's Education Headquarters. Training Psych Stud. 2005;2:173-80.

10. Vafaei SM. Examination of Decision Making Methods of Health Nursing's Managers Working in Hospitals Dependent on Khorasan Medical Sciences' University [in Persian]. Nursing Midwifery Coll J. 2004;2(2):1-8.

11. Noruzinejhad F, Nuritajer M, Jafarjalal A, Hoseini F. Examination of Head Nurses' Cooperation Rate in Decision Making and its Relation to Their Satisfaction of Cooperation in Decision Making [in Persian]. Iran's Nursing J. 2005;19(45):7-16.

12. Murdick R, Ross J, Clggett J. Information Systems for Modern Management.New Delhi: Prentice Hall of India; 1990.

13. Salehi S, Pahlavanzade S, Vajarahi H. Faculty Members' Cooperation Rate in Decision Making of Managers in Isfahan's Medical Sciences' Colleges from the Viewpoint of Managers and Faculty's Members [in Persian]. Iran J Educ Med Sci .2002;6:35-42.

14. Hakimipur AG. Decision Making in Management, Function of Markov Chains' Theory in Management's Decision Making.Mashhad: Astan ghods razavi;1998.

15. Monahan GE. Management decision making.Cambridge: Cambridge University Press; 2000.

16. Farzandipur M, Rangrez Jadi F, Musazi GA. Examination of Managers' Utilization of Statistical Indicators in Administrating Matters Related to Kashan's Hospitals in 2002. Feiz Sci Res J. 2002;27:92-8.

17. Daft RL. Organization Theory and Design.Boston: South-Western College Pub; 2002.

18. Alvani M. Decision Making and Determination of Governmental Policy.Tehran: Samt; 1994. 